\title{
A problematização dos saberes de gênero no ambiente escolar: uma proposta de intervenção à formação docente
}

\author{
The problematization of gender knowledge in the school \\ environment: an intervention proposal for teacher training
}

Fabiane Freire França*

Geiva Carolina Calsa**

RESUMO

O objetivo deste estudo consiste em investigar as representações sociais de gênero de professores e professoras que atuam em $5^{\underline{a}}$ e 6 ${ }^{\text {a }}$ séries de uma escola pública da cidade de Sarandi/PR. Em razão da importância política e social da discussão sobre gênero, foram levantadas as seguintes problematizações: Quais as representações sociais de professores e professoras a respeito de gênero? Esse conceito pode ser repensado por meio de uma intervenção pedagógica? Para tanto, realizamos entrevistas com os/as docentes e um processo de intervenção pedagógica com discussões em grupo com o intuito de repensar o gênero em um contexto sócio-histórico que produz relações de poder. Tomou-se como fonte de dados as verbalizações dos professores e das professoras antes, durante e depois do processo de intervenção pedagógica. Os resultados deste artigo apontaram um movimento de opiniões e definições do conceito de gênero apresentado pelos/as professores/as após o processo de intervenção pedagógica diferente de sua postura inicial. Esse movimento evidenciou uma abertura maior à compreensão do conceito de gênero contrário às representações iniciais dos sujeitos. Consideramos que tais resultados revelam a necessidade de maiores discussões sobre o gênero no ambiente escolar.

PALAVRAS-CHAVE: Educação. Gênero. Formação docente. Intervenção pedagógica. Formação de conceitos..

\section{ABSTRACT}

The aim of this study is to investigate the social representations of gender in teachers who work in 5th and 6th grades at a public school in the city of Sarandi/PR. Due to the political and social importance of discussion of gender, it have been raised the following problematizations: What are the social representations of teachers about gender? This concept could be rethought through a pedagogical intervention? We made interviews with the teachers and a process of pedagogical intervention with group discussions in order to rethink the genre in a socio-historical context that produces power relations. It was taken as data source the verbalizations of teachers before, during and after the process of pedagogical intervention. The results of this paper showed a movement of views and definitions of gender presented by the teachers after the pedagogical intervention which were different from their initial stance. This movement showed more a more open understanding to the concept of gender representations contrary to their initial representations. We believe that these results reveal the need of more discussion about gender in the school environment.

KEY-WORDS: Education. Gender. Teacher training. Educational intervention. Concept Formation.

\footnotetext{
* Formada em Pedagogia pela Universidade Estadual de Maringá.. Mestre em Educação pela mesma instituição. Docente colaboradora da Faculdade Estadual de Ciências e Letras de Campo Mourão e integrante da Associação Brasileira de Psicopedagogia-ABPpPR. Email: fabianefreire@ibest.com.br

**Professora Doutora do Departamento de Teoria e Prática da Universidade Estadual de Maringá. Email: gccalsa@uem.br
} 


\section{Introdução}

Pesquisas relacionadas ao gênero no âmbito escolar, como a de Nadia Geisa de Souza (2000), indicam que a representação do corpo e da identidade de professores/ as reproduz estereótipos do ser mulher, ser mãe e ser feminina. Pautada em relatos de docentes de Biologia, a autora constatou a persistência de abordagens embasadas no discurso médico, que legitima socialmente a função da mulher como mãe, ou seja, reprodutora. As comprovações da autora vão ao encontro de conclusões anteriores de Foucault (1984, 1988) sobre a biologização e a medicalização da identidade dos gêneros.

Nesta direção, o objetivo deste estudo consiste em investigar as representações sociais de gênero de professores e professoras que atuam em $5^{\underline{a}}$ e $6^{\underline{a}}$ séries de uma escola pública da cidade de Sarandi/PR. Optou-se por trabalhar com docentes devido ao papel que têm na formação da identidade de seus alunos e alunas. Um processo de discussão e (re)organização de seus conceitos de gênero por meio de grupos de estudos seria, portanto, um caminho para repensar seus conceitos de forma mais crítica e contextualizada.

A produção das desigualdades de gênero é decorrente de processos sociais mais amplos que designa as posições dos sujeitos no que diz respeito ao seu corpo, à sua sexualidade, raça, classe social, religião, etc. Em razão da importância política e social da discussão sobre gênero e os resultados de estudos contemporâneos sobre o conceito de homem e de mulher encontrado na instituição escolar, foram levantadas as seguintes problematizações: Quais as representações sociais de professores e professoras a respeito de gênero? Esse conceito pode ser repensado por meio de uma intervenção pedagógica?

Para tanto, realizamos entrevistas com os/as docentes e um processo de intervenção pedagógica com discussões em grupo com o intuito de repensar o gênero em um contexto sócio-histórico que produz relações de poder. Tomou-se como fonte de dados as verbalizações dos professores e das professoras antes, durante e depois do processo de intervenção pedagógica.

Caracterizamos esta análise como uma pesquisa-ação participativa, ao considerar a pesquisa um instrumento de "(re)construção" do conhecimento do ponto de vista ético, bem como um instrumento privilegiado para a realização de investigações sobre a escola e a prática docente por meio de problematizações.

Alguns dos interlocutores desta discussão foram: Guacira Lopes Louro (1997, 2007), Michel Foucault (1984, 1988), Dagmar Meyer (1999, 2003), Tomaz Tadeu da Silva (2007), Marisa Vorraber Costa (1999, 2002), dentre outros/as. As discussões 
possibilitaram uma proposta de desconstrução de alguns paradigmas sobre o gênero, como a justificativa da desigualdade entre homens e mulheres tomando-se por base as diferenças biológicas em um processo de reconhecimento da representação de identidades femininas e masculinas como construções sociais carregadas de poder. Neste viés, as identidades de gênero e sexuais não são naturais, são construções humanas que envolvem valores, sentimentos e desejos.

Os resultados deste artigo apontaram um movimento de opiniões e definições do conceito de gênero apresentado pelos/as professores/as após o processo de intervenção pedagógica diferente de sua postura inicial. Esse movimento evidenciou uma abertura maior à compreensão do conceito de gênero contrário às representações iniciais dos sujeitos. Manter o grupo em constante discussão e conflito de idéias foi um recurso que se mostrou satisfatório para romper com os paradigmas e práticas hegemônicas sobre gênero.

A produção dos saberes e das identidades de gênero implica problematização, daí a necessidade de interrogar as regras e os efeitos das práticas sociais que, ao legitimarem determinados conteúdos, pensamentos e ações como verdades universais e absolutas, podem silenciar outras categorias possíveis. Sabe-se que mudar esse quadro social de discriminação e preconceito não acontece por meio de um único trabalho. Porém, a discussão acerca do gênero parece ter sido significativa para a formação desses homens e mulheres que assumiram as identidades de professores e professoras. Consideramos que tais resultados revelam a necessidade de maiores discussões sobre o gênero no ambiente escolar.

\section{Gênero e Educação: uma Perspectiva Crítica das Relações de Poder no Contexto das Práticas Pedagógicas}

O tema em questão - gênero, pouco discutido pelo currículo escolar - vem sendo ensinado na escola com base em mitos, preconceitos e discriminações, conforme mostram estudos anteriores (LOURO, 1997, 2007; WEEKS, 2007). De Roseli Pereira da Silva (2007) tomamos emprestada a definição de preconceito como uma idéia preconcebida, baseada na dificuldade do indivíduo de se colocar no lugar do outro. J á a discriminação refere-se à ação contra um indivíduo ou grupo pautada em padrões de preferências. A autora salienta que, na instituição escolar, a realização de debates sobre quem sofre ou sofreu algum tipo de preconceito possibilita aos indivíduos lidar com as diferenças, até mesmo de uma maneira consciente e crítica. Para ela, toda forma de educação trata de valores e a função dos/as docentes, nesta instituição, não é mostrá- 
los como "certos" ou "errados", mas explicitar os seus significados por intermédio de perspectivas diversas - convergentes, divergentes e contraditórias.

Segundo Scott (1995), o termo gênero foi proposto por mulheres que buscaram mudar os paradigmas de abordagem científica e não-científica sobre o gênero feminino. Discussões acadêmicas nesse campo não se centram apenas na história das mulheres, mas na compreensão do movimento histórico dos dois gêneros. Não se pautam em uma metodologia que aborda apenas a "nova história das mulheres", e, sim, uma "nova história", na qual as relações de classe, religião, etnia, gênero e sexualidade são articulados.

Foucault (1988) salienta que desde o século XVIII a sociedade vive uma fase de repressão sexual. Com a ascensão da burguesia o sexo se reduziu a sua função reprodutora e o casal procriador passa a ser o arquétipo. O que não corresponde à regra torna-se "anormal" - é excluído, negado, reduzido ao silêncio. No entanto, a sociedade burguesa permite algumas concessões. Ela restringe as sexualidades negadas a lugares onde possam dar lucros, como por exemplo, as casas de prostituição.

Para Louro (1997, 2000), é preciso problematizar os conceitos de gênero e sexualidade que são apresentados no contexto escolar por meio de um processo desconstrutivo que supõe o questionamento da identidade dos sujeitos no que diz respeito a valores e normas.

Ao refletir sobre a formação da identidade dos sujeitos pelo campo da instituição escolar, por exemplo, pode-se considerar que a ação pedagógica é caracterizada por uma violência simbólica que tem como meta inculcar certas significações impondo o arbitrário cultural de determinado grupo ou classe como uma cultura legítima. O poder da violência simbólica impõe significações como legítimas e dissimula as relações de poder.

Para Foucault (1988) o poder está presente em todos os lugares, é instável, pois provém e se espalha por todas as partes. Por essa razão, não faz sentido procurar a existência primária dos mecanismos de poder em um ponto central. O autor busca evidenciar o aparecimento de saberes a partir de possibilidades externas aos próprios saberes como peça de relações de poder (genealogia). Busca ainda, demonstrar que não existe uma teoria geral de poder, pois este não possui característica universal, ou seja, não existe algo unitário e global chamado poder, mas sim formas heterogêneas em constantes transformações.

Em uma perspectiva complementar, Louro (1997, p. 61) destaca que a divisão do trabalho, oriunda da estrutura de produção capitalista, permitiu que se organizassem politicamente outros grupos sociais, além da classe, baseados na raça, etnia, 
sexualidade e gênero. A partir das idéias produzidas por esses novos grupos, as relações de poder - que atribuíam às autoridades decisões "inquestionáveis" sobre o panorama social - foram questionadas. São exemplos disso, os gestos e sentidos "produzidos no espaço escolar e incorporados por meninos e meninas, tornando-se parte de seus corpos".

Os estudos de gênero vinculados aos movimentos sociais permitiram o questionamento político e o processo de reflexão crítica sobre a situação das mulheres nas sociedades modernas. Posteriormente, esses estudos romperam com o paradigma de apenas compreender a condição das mulheres, propondo-se a refletir sobre os processos de construção da feminilidade e da masculinidade, e suas relações com a sexualidade e a representação dos corpos.

Tais estudos problematizaram o gênero e a sexualidade, com o intuito de romper com a visão binária, já mencionada (dois sexos e dois gêneros) e biologista, ou seja, quem nasce mulher terá, necessariamente, desejos sexuais por homens e se adequará às expectativas do gênero feminino. A problematização desses conceitos busca questionar as classificações sociais que padronizam gênero, sexualidade e corpo, compreendendo que existem identidades que não se enquadram aos padrões tradicionais dominantes. Assim, nem todas as mudanças de gênero indicam, necessariamente, mudanças no plano da sexualidade dos indivíduos e vice-versa.

De acordo com Louro (1999), a produção dos sujeitos está articulada às relações de poder que vigoram como "naturais" e que apresentam as diferenças como estigmas: ser gordo, ser pobre, ser velho, ser homossexual, ser mulher, etc. Estes estigmas geram discriminações e limitam as possibilidades de inclusão dos sujeitos na escola, bem como, afetam suas possibilidades de aprendizagem, entre outras conseqüências sociais, culturais, econômicas e éticas.

Louro (1999) afirma que a sexualidade, os corpos e os gêneros vêm sendo descritos, compreendidos, explicados, regulados, saneados e educados pelas instâncias sociais. Estado, igreja, família, escola, ciência - instituições tradicionais - concorrem atualmente com a mídia, com grupos organizados de feministas e de "minorias sexuais" que pretendem também ter voz sobre a sexualidade, o exercício do prazer, as possibilidades de experimentar os gêneros, de transformar e viver os corpos.

Lembrando desses aspectos, Roseli Silva (2007) recomenda uma abordagem escolar que trate a identidade e a diferença como questões políticas, ou seja, como produções histórico-sociais. Nesse caso, o planejamento curricular não se preocuparia em reafirmar a diversidade de valores, crenças e identidades, e sim problematizar o modo como os conceitos são produzidos socialmente. Isso significa entender que 
mecanismos buscam fixar as identidades seja de gênero, raça, etnia ou sexualidade. Para tanto, é necessária à escola a opção por uma teoria que explique o processo de produção dos conceitos em questão.

\section{Desenvolvimento da Pesquisa}

Para responder a problematização do presente artigo foram selecionados 12 professores, oito mulheres e quatro homens, do ensino fundamental da cidade de Sarandi/PR, sendo os critérios restritos a atuação dos mesmos em $5^{\text {a }}$ e $6^{\underline{a}}$ séries, devido a uma demanda maior de dúvidas e anseios nessa etapa sobre os conceitos de gênero e sexualidade referidos pela escola.

A atividade em destaque, neste artigo, refere-se às entrevistas individuais antes e após o processo da intervenção pedagógica com o grupo de professores voluntários. Vale lembrar que, embora as entrevistas tenham seguido um roteiro, cada encontro teve um desenvolvimento particular em função das características da interação entrevistado/ entrevistada/ entrevistadora.

Das cinco questões do roteiro, três referiam-se a aspectos gerais do tema gênero e duas a excertos de jornal sobre a identidade de mulheres. Os dois excertos selecionados mostram a mulher em contextos diferentes: quando a mulher "deve" se submeter aos padrões estabelecidos pelo homem e quando expressa "autonomia" para modificar o seu corpo. Uma vez que a maioria dos/as entrevistados/as da pesquisa eram mulheres (67\%) considerou-se relevante a apresentação das questões especificamente referentes à constituição de sua identidade. Optou-se por ressaltar neste artigo a primeira questão da entrevista: O que é gênero para vocêe As verbalizações dos/as professores/as foram transcritas na íntegra, sem correção dos vícios de linguagem, deslizes gramaticais ou erros de concordância próprios da linguagem oral.

\section{Apresentação e Discussão dos Resultados}

Após a leitura das respostas dos/as docentes às duas entrevistas, foi possível construir categorias que sugerem as impressões dos/as docentes em relação ao tema gênero. As suas respostas não foram consideradas como seu pensamento absoluto sobre o tema e sim manifestações apreendidas pela pesquisadora em um determinado momento.

Na primeira entrevista, conforme nossas notas de campo, as reações dos/as professores/as sugeriram diferentes graus de envolvimento com o conceito de gênero e 
foram tais aspectos analisados no estudo. Neste sentido, apresentaram-se como manifestações que podem representar o pensamento do sujeito sobre o tema e, certamente, dependeram de sua interação com o assunto focalizado e com a entrevistadora, entre outros elementos envolvidos neste tipo de atividade de pesquisa. A segunda entrevista foi realizada com o intuito de verificar se, por meio das discussões criadas durante o processo de intervenção pedagógica, ocorreu um movimento de reorganização do conceito de gênero apresentado pelos/as professores/as. As falas dos sujeitos, após a intervenção, mostraram-se diferentes em comparação com as primeiras.

As respostas à pergunta $\mathbf{O}$ que é gênero para você foram organizadas em três categorias conceituais (Tabela 1): contexto sociocultural; sexo feminino e masculino; e não respondeu/não explicou. Na primeira entrevista, quase todos/as os/as docentes entrevistados/as (84\%) responderam que gênero restringe-se à diferença biológica dos sexos como opostos. Apenas uma professora - P1(M) - (8\%) apontou o contexto sociocultural como um dos elementos envolvidos nesta temática; e um professor - $\mathrm{P} 9(\mathrm{H})$ - $(8 \%)$ disse não saber responder a questão. Na segunda entrevista, contrariamente, a categoria que mais se destacou foi a relacionada ao contexto sociocultural: 92\% afirmaram que o conceito de gênero corresponde a uma construção social e pessoal envolvida pelo contexto cultural (Tabela 1). A fala de P4(M) exemplifica as respostas dadas: “É construído socialmente, pois ele pode ser homem e gostar de outro homem, é construído socialmente, não é a característica física que determina o gênero".

Tabela 1 - Questão 1: Comparação entre a primeira e a segunda entrevista

\begin{tabular}{lll}
\hline Categorizações conceituais & Entrevista 1 & Entrevista 2 \\
\hline A) Contexto sociocultural & $8 \%(1)$ & $92 \%(11)$ \\
B) Sexo feminino e masculino & $84 \%(10)$ & $0 \%(0)$ \\
C) Não respondeu/ não & $8 \%(1)$ & $8 \%(1)$ \\
explicou & & \\
Total & $100 \%(12)$ & $100 \%(12)$ \\
\hline
\end{tabular}

Fonte: Dados obtidos a partir das Entrevistas

A modificação da fala dos/as docentes parece resultar das características das sessões de intervenção pedagógica. Uma dessas características - o movimento de (des)construção dos conceitos prévios dos docentes e abertura para outros posicionamentos sobre gênero - foi citada pelos/as professores/as como a origem das 
modificações ocorridas em sua forma de pensar. A fala da professora P2(M) exemplifica esta situação:

P2(M) - (rsrs) Então, tá complicado, foi desconstruído né tudo aquilo que eu imaginava tá confuso e agora estou em fase de construção. Eu não aceitei bem ainda o que é, eu acho que como você já havia falado, é construído, gênero é construído pela sociedade que é o papel da mulher, o papel do homem. Então, eu to ainda assimilando essas questões ainda.

A seguir, são explicadas, com maior detalhamento, as características de cada uma das três categorias de respostas referentes à primeira questão das entrevistas.

\section{Categoria A: contexto sociocultural}

Na primeira entrevista, apenas a professora $\mathrm{P} 1(\mathrm{M})$ (8\%) considerou a construção do gênero relacionado ao contexto cultural e social dos indivíduos. "Mulheres sofrem questão de discriminação de gênero [...] Tudo depende do contexto de onde você está discutindo gênero". A fala da professora parece corresponder à idéia de Rachel Soihet (2004) para quem a sociedade contemporânea divide homens e mulheres de acordo com as regiões, os costumes, os valores, a educação e a cultura. Para a autora, não é à-toa que, durante décadas, criaram-se estratégias para sustentar a desigualdade de homens e mulheres pautada, sobretudo, na biologia e na medicalização dos corpos e da mente.

A reportagem "Pisando no 'sexo frágil'”, na revista Nossa História (SOIHET, 2004 p. 17), apresenta momentos da passagem do século XIX para o século XX, nos quais as mulheres eram alvo de descrédito em suas lutas e movimentações pelo atendimento aos seus direitos garantidos legalmente. Tal descrédito era reforçado pelos discursos médicos da época. Cesare Lombroso, conceituado criminologista do século XIX, afirmava que a mulher normal teria algumas características negativas semelhantes à criança, como: exagerado ciúme, tendência à vingança e um senso moral deficiente. "De maneira geral, esses defeitos seriam neutralizados pela maternidade, frieza sexual e inteligência menor". Nesta direção, mulheres inteligentes seriam perigosas, porque se mostrariam criminosas natas.

Supomos que afirmações como estas ainda sejam reproduzidas e naturalizadas no mundo contemporâneo por meio de brincadeiras, piadas e gestos cotidianos, resultado de conhecimentos naturalizados e absolutizados, transmitidos pelas famílias, pela mídia e pela própria instituição escolar. Em uma perspectiva oposta, uma concepção de gênero que considere a produção cultural e histórica, como aponta Louro 
(2007), exige reconhecer que os gêneros se "fazem" sempre com as marcas de cada cultura e contexto social. A autora complementa que as práticas de linguagem produzem sujeitos "femininos" e "masculinos" por meio dessas "marcas", que são gravadas na memória dos indivíduos. Essa foi a orientação predominante das respostas dos/ as professores/ as na segunda entrevista.

Em entrevista, após o processo de intervenção pedagógica, os/as docentes P2(M), P4(M), P6(H), P7(H) e P9(H) definiram gênero como uma construção social de homens e mulheres, que abarca também escolhas pessoais. A fala de P6(H) representa as considerações referentes a essa categoria: "A sociedade reflete na constituição do gênero, mas cada pessoa tem sua maneira própria de escolher seu próprio gênero". Apontaram ainda que as reflexões sobre o conceito envolvem a formação de cada indivíduo em suas práticas cotidianas: $\mathrm{P9}(\mathrm{H})$ "o indivíduo traz na sua formação, no seu dia-a-dia. Isso pra mim que é o gênero". P1(M) e P8(M) enfatizaram a formação da identidade em contato com várias instâncias sociais: P1(M) "Gênero é identidade, a identidade que a pessoa tem né, seja ela masculina ou feminina" e P8(M) "gênero eu acredito que é formado, é como o indivíduo forma a identidade dele, através da::: de conhecimento, de envolvimentos com pessoas, com o meio escolar, em casa, em qualquer lugar, porque ele vai formando a identidade dele que pode ser masculina, feminina". A formação simultânea do corpo, da sexualidade e do gênero como produto social foi destacado também pelas professoras P10(M), P11(M) e P12(M).

Ainda assim, o professor P3(H) expressou certa dúvida, confundindo gênero com sexualidade, embora demonstre ter ultrapassado o binarismo absoluto feminino e masculino: "Gênero pra mim hoje não é só a questão de homem e mulher, sexo masculino e feminino. Nos tempos que nós estamos vivendo hoje gênero é mais do que isso né, é uma orientação sexual!”. Cabe destacarmos que gênero não corresponde à orientação sexual, entretanto, apesar das confusões conceituais e diferentemente da primeira entrevista, o professor mostrou abertura a novas possibilidades em relação ao conceito de gênero.

A manifestação de outros elementos, que não predominantemente os biológicos, nas falas dos/as professores/as sugere o início de um movimento que pode continuar após a pesquisa, de reflexão sobre a construção de seus conceitos. Bell Hooks (2007, p. 118), comentando sua prática como professora, segundo nossa opinião apropriadamente, lembra que é necessário “[...] transformar consciências, dotar estudantes de modos de conhecimento que as capacitem a conhecer melhor a si mesmas e a viver no mundo mais plenamente [...]". 


\section{Categoria B: sexo feminino e masculino}

Na primeira entrevista, 84\% dos/as docentes - P2(M), P3(H), P4(M), P5(M), $\mathrm{P} 6(\mathrm{H}), \mathrm{P} 7(\mathrm{H}), \mathrm{P} 8(\mathrm{M}), \mathrm{P} 10(\mathrm{M}), \mathrm{P} 11(\mathrm{M})$ e $\mathrm{P} 12(\mathrm{M})$ - definiram gênero restringindo-o à distinção sexual: sexo masculino e feminino. Os gêneros foram considerados construções opostas com base na diferenciação do sexo feminino e masculino. Para ilustrar esta categoria, foram transcritas em sua íntegra as respostas dos/as docentes: P2(M), P3(H), P8(M) e P10(M) “Masculino e feminino”; P4(M) “Um conjunto de coisas que tem as mesmas características; um grupo de mulheres que tem suas características físicas iguais”; P5(M) "É feminino, é masculino, onde você vai definir do ser humano, se ele é do gênero masculino ou feminino"; P6(H) "Eu sou biólogo né, e, na Biologia, a gente fica um pouco confuso em relação a definir o que é sexualidade, o homem, a mulher, o macho, a fêmea. De um modo geral, é a questão da divisão dos sexos mesmo"; P7(H) "Essa questão de diferença sobre feminino e masculino que eu conheço. De estudo, eu não sei"; P11(M) "Masculino e feminino, mas tem a questão que a gente tinha abordado lá no curso né3, pode ter um determinado grupo é assim, são questões assim, o homem, a mulher, as questões aí que cada um coloca que cada um tem, por exemplo, de seu corpo"; P12(M) "Hormônios masculino e feminino".

Guacira Louro (2000) considera, de uma posição contrária à polarização entre os sexos, a expressão de um esquema de pensamento aparentemente lógico, que dificulta a criação de outras formas de pensar sobre o tema. Como demonstra Weeks (2007, p. 63), a definição da masculinidade e feminilidade como "[...] características distintas dos homens e das mulheres biológicos" resulta em uma distinção "natural" e absoluta.

Louro (2000) acrescenta que, no contexto educacional, a manutenção desse esquema acaba por legitimar uma ordem universal baseada nas distinções biológicas, como supomos é o caso dos/as docentes entrevistados na presente pesquisa: pelo menos a metade deles respondeu claramente nesta direção. Embora apareça na escola como uma aprendizagem de "papéis" masculinos e femininos (concepção que parece se ligar a um paradigma de identidade de gênero), a autora acredita que gênero (assim como a classe ou a raça) é mais do que uma identidade aprendida, é mais do que uma aprendizagem de papéis. Sua produção ocorre por meio das instituições, símbolos, formas de organização, discursos e doutrinas presentes em cada tempo e espaço social em um movimento recíproco em que as instâncias sociais são instituídas pelos gêneros e também os instituem.

\footnotetext{
${ }^{3}$ Diz respeito ao curso-convite já explicitado.
} 
Continuando sua argumentação, Louro (2000) assinala a importância da distinção estabelecida entre os conceitos de gênero e sexo para fazer frente às interpretações biologistas - que viam nas diferenças biológicas uma justificativa para as desigualdades entre homens e mulheres. Não há como negar uma estreita imbricação entre o social e o biológico, embora não deste modo, porque a construção dos gêneros é, de fato, um processo social e histórico que envolve o sexo e os corpos dos indivíduos.

Como para a maioria das pessoas, para os/ as entrevistados/ as, a constituição de seu sujeito "feminino" e "masculino" ocorreu a partir da linguagem e das práticas sociais transmitidas em sua formação familiar, escolar e/ ou religiosa. É dessa maneira que aprenderam a ser homem e mulher e é assim, como demonstram suas respostas posteriores ${ }^{4}$, que parecem ensinar a seus alunos/ as.

Na segunda entrevista, nenhum sujeito referiu-se ao conceito de gênero restrito ao sexo masculino e feminino. Notamos que o processo de intervenção pedagógica contribuiu para o repensar dos/as docentes sobre a construção social do conceito de gênero, que, até então, era enfatizada por um único viés - o biológico.

\section{Categoria C: não respondeu/ não explicou}

Durante a primeira entrevista, o docente P9(H) disse: “É:::". Não respondeu a questão e começou a ler a seguinte. Na segunda entrevista, apenas uma professora P5(M) foi classificada nesta categoria, embora com ressalva, visto que afirmou compreender que gênero é mais do que a divisão sexual: "hoje, eu vejo como gênero aonde a gente pode tá definindo como além do sexo". Sua fala apresentou um movimento em relação a sua resposta da primeira entrevista, mas não explicou a significação do "ir além", mesmo após solicitação durante a entrevista. Tanto P9(H) quanto P5(M) evidenciam que há ainda muito que problematizar, discutir e entender sobre o assunto, em especial no ambiente escolar, que muito influencia na formação da identidade dos indivíduos.

As respostas à segunda questão da primeira e segunda entrevista, Gênero, sexualidade e corpo têm alguma relação? Qual? Explique., foram organizadas em três categorias conceituais: relação sociocultural, relação biológica e não explicou. Na primeira entrevista, os dados sugerem uma visão restrita do conceito de gênero e, posteriormente, um movimento de ampliação desse conceito, abarcando aspectos

\footnotetext{
${ }^{4}$ Afirmações manifestadas nas entrevistas individuais e durante as sessões de intervenção pedagógica.
} 
sociais e culturais. Na verdade, entre as duas entrevistas, há uma inversão de resultados.

Tabela 2 - Questão 2: Comparação entre a primeira e a segunda entrevista

\begin{tabular}{lll}
\hline Possíveis Categorizações & Entrevista & Entrevista \\
& 1 & 2 \\
\hline A) Relação sociocultural & $17 \%(2)$ & $92 \%(11)$ \\
B) Relação biológica & $75 \%(9)$ & $0 \%(0)$ \\
C) Não respondeu/ não explicou & $8 \%(1)$ & $8 \%(1)$ \\
\hline Total & $100 \%(12)$ & $100 \%(12)$ \\
\hline
\end{tabular}

Fonte: Dados obtidos a partir das Entrevistas

Na primeira entrevista, apesar de $17 \%$ dos/as entrevistados/as considerarem a existência desta relação e justificá-la por razões sociais e culturais, 84\% manifestaram que gênero, sexualidade e corpo são conceitos que combinam entre si pautados/as em uma concepção biologista. Isso significa que o homem tem corpo masculino e sua sexualidade "deve" ser masculina, o mesmo "deve" ocorrer com o corpo e a sexualidade da mulher. As respostas da maioria dos/as docentes correspondem às afirmações de Louro (2007, p. 11), segundo as quais a sexualidade é algo que mulheres e homens acreditam possuir "naturalmentce", idéia sustentada pela hipótese de que todos vivem seus corpos da mesma forma. "A inscrição dos gêneros - feminino ou masculino - nos corpos é feita, sempre, no contexto de uma determinada cultura e, portanto, com as marcas dessa cultura".

Na segunda entrevista, os resultados foram inversos: $92 \%$ dos/as docentes afirmaram existir esta relação e apresentaram justificativas sociais, ainda que incipientes e incompletas:

P2(M) - ::: rsrsrs sexualidade e corpo, não! Porque de repente, ele tem um corpo feminino e age, tem ações, atitudes masculinas, pensa e age como masculino. Então a opção sexual dele não é a mesma de acordo com o corpo dele ou corpo dela, então, acho que em alguns casos não! Não tem relação. porque gênero no caso, masculino e feminino, as ações, tanto o masculino como o feminino pode ter várias atitudes, independente, se isso é coisa de mulher, ou isso é coisa de homem! Nós podemos fazer tudo, o comportamento que não são específicos, não quer dizer que um comportamento é específico do homem ou da mulher, o homem pode lavar a roupa, isso é muito bom (risos) e da mesma forma a mulher sai de casa, trabalha, os dois podem fazer as mesmas ações sem "ah isso aí é coisa prá homem! Ou prá mulher também!”. 
P2(M), mesmo considerando as várias possibilidades de ser homem e mulher, independente das características femininas e masculinas, ainda trata a questão da orientação sexual como opção sexual (LOURO, 2007, p. 28-30). Porém o conceito de gênero já foi repensado a partir de novas possibilidades de comportamento de homens e mulheres.

\section{Categoria A: sim, uma relação sociocultural}

Em relação à primeira entrevista, as respostas de P1(M) e P6(H) indicam a existência de aspectos culturais que envolvem o conceito de gênero, corpo e sexualidade. P1(M) comentou a importância dos valores e do contexto na formação de homens e mulheres; P6(H), a exploração do culto ao corpo e à beleza. Para a primeira professora, o conceito de gênero envolve a tradição, os valores, a crença, e a própria educação dos indivíduos, como mostra seu depoimento:

P1(M) - Eu acredito que tudo tem relação. Gênero é dependendo da questão cultural, que difere muito de como os homens são criados, de como as mulheres são criadas. A sexualidade então e o corpo, a gente vê diferenças, almas femininas em corpos masculinos, ou corpos masculinos em almas femininas né, então é tudo muito relativo, ao mesmo tempo em que tudo está muito relacionado.

Sua fala lembra a dimensão cultural e social do gênero que, segundo Louro (1997, 2000, 2007), é fundamental para a distinção entre gênero, corpo, sexo e sexualidade. Gênero, sexualidade e corpo são considerados construtos humanos e, portanto, culturais. Os estudos de gênero consideram a construção da feminilidade e masculinidade. No corpo, a natureza biológica se transforma em função do contexto histórico e social; enquanto a sexualidade define a orientação sexual do indivíduo que pode ser heterossexual, homossexual ou bissexual. O sexo refere-se aos atributos biológicos de reprodução, que definem os seres como homem ou mulher.

Gênero e sexualidade - deduzidos de uma "base natural" dos indivíduos - são atributos que se inscrevem e se expressam nos corpos mediante as artimanhas e os artifícios da cultura. Ainda assim, não são definições seguras e estáveis, mas históricas. Isso quer dizer que os corpos não são "lidos" ou "compreendidos" do mesmo modo em qualquer tempo ou lugar, nem que seja atribuído valor semelhante às mesmas características corporais em culturas distintas.

O professor P6(H) relaciona os conceitos de gênero e sexualidade ao culto ao corpo, ou seja, a uma cultura que produz e valoriza corpos "perfeitos". 
P6(H) - Bem, eu acho que tirando a parte biológica, como a gente pensa::: Na parte biológica, entre eles (rsrs), a gente pensa que tem toda essa questão, o corpo, um culto ao corpo, o corpo a promover a sexualidade, a representação de um corpo bonito. Muitas crianças vêem o corpo, meninos com 12, 13 anos de idade, na puberdade, pensam assim "é a hora da sexualidade!". [...] Eu acho que a relação é muito grande, o corpo, o culto ao corpo, uma forma de chamar a atenção, o belo que desperta a sexualidade. O jovem, o corpo tudo isso tem a ver com sexualidade na sociedade.

A fala deste professor vai ao encontro das representações sociais do homem e da mulher presentes nos meios midiáticos, que olham e exibem o corpo pela sua sensualidade. Louro (2000) destaca que essas representações convertem a imagem da beleza e da sedução em um ícone da sociedade de consumo. Ser bela ou belo é ser, necessariamente, atraente e sensual para o "outro". Tornar-se mais atraente ao olhar do outro é tanto uma condição como um anseio que está impresso nos detalhes do corpo de cada indivíduo. Finalmente, levando em conta o referencial teórico da pesquisa, supomos que as posições de P1(M) e P6(H) mostram-se abertas a levar para a escola uma visão menos preconceituosa e excludente do conceito de gênero.

Na segunda entrevista, 92\% dos/as docentes abordaram a representação social desses conceitos, bem como questões relativas a sentimentos e sensações envolvidos no processo de construção. P7(H) - "A questão da sexualidade que a gente vê que tem toda a questão de sentimentos e sensações que, também não era muito claro pra mim, e ainda não está muito claro ainda, mas já deu uma melhorada”. É evidente que professores e professoras não deixaram de considerar a relação biológica existente entre gênero, corpo e sexualidade, no entanto, passaram a contemplar em suas falas essa relação como uma construção social e temporária: P6(H) “Acho que estão ligadas, porque como faz parte a representação social do papel de gênero, corpo faz parte, também tem uma representação pela questão do padrão de beleza e a sexualidade [...]".

Embora as falas dos/ as docentes, em geral, tenham se modificado e apresentado outras possibilidades de compreensão de gênero, sexualidade e corpo, ainda apresentaram confusões, resistência e conflitos:

P8(M) [...] Só que depois do curso eu tive assim um outro olhar pra eles (refere-se a quem foge ao padrão hegemônico). Antes era só assim "ai que safadeza!" Era assim bem preconceituoso, claro que agora eu não (rsrs) aceito totalmente! Mas, não olho mais com esse olhar, [...] daí você já pensa, de repente não quer essa vida, sofre muito, como a P5(M) falava, eu não tinha esse pensamento não! Era preconceituosa mesmo e não pensava no lado deles não! 
Ao comparar as respostas da primeira com a segunda entrevista sobre a conceituação de gênero, notamos um percurso em direção à compreensão do conceito em seu contexto social e cultural. Para P3(H), a relação entre gênero, sexualidade e corpo existe e, ao mesmo tempo, não existe, porque "de repente a pessoa pode nascer, como eu acabei de dizer, no corpo masculino, mas a sexualidade dele puxa assim mais para o feminino”. Na seqüência, a professora P4(M) parece concordar com o professor em sua fala:

P4(M) - O gênero é essa construção social, do ser que não é uma coisa, diferente do corpo que é físico, nasce com pênis, ele é homem, é físico, o corpo. Então na verdade não tem relação, não quer dizer que porque ele nasceu com um pênis que ele vai ser homem, porque é cultural é construído socialmente. Ele pode ter pênis e gostar de homem, então, tem relação, mas não determina.

Apesar de P3(H) e P4(M) levantarem uma gama de interpretações inexistentes na primeira entrevista, na segunda, persistiram confusões conceituais em suas verbalizações: O que $\mathrm{P} 3(\mathrm{H})$ quer dizer com "a sexualidade dele puxa assim mais para o feminino"? P4(M), em sua resposta, em um primeiro momento separou a questão biológica da social, evidenciou contradição quando afirmou que, se "nasce com pênis, ele é homem" e, na seqüência, "não quer dizer que porque ele nasceu com um pênis que ele vai ser homem, porque é cultural", como se fossem duas questões distintas.

De acordo com Louro (2000), ao resgatar a aliança história-biologia em uma historicização do biológico, seria possível pensar, por exemplo, nas profundas modificações nos hábitos alimentares, nas condições de vida ou em aparatos tecnológicos que, ao serem incorporados no cotidiano das pessoas, alteraram algumas de suas características, como a duração média de vida, o envelhecimento, a capacidade motora, a força muscular, a forma de geração de filhos, etc. Um dos caminhos apontados pela autora seria, então, evitar a polarização social/natural, compreendendo que o gênero possui uma dimensão e expressão tanto social quanto biológica.

\section{Categoria B: Sim, uma relação biológica}

Na primeira entrevista, a maioria dos entrevistados (75\%) afirmou que, se o corpo é masculino, o gênero e a sexualidade também "devem" sê-lo. Para esses sujeitos, gênero se refere à identidade biológica da pessoa, e tanto o homem como a mulher devem cumprir as regras sociais consideradas "naturais" no que se refere ao seu próprio corpo e ao do outro. A seguir, a fala de P4(M), que representa essa categoria: 
P4(M) - A questão da sexualidade e o gênero masculino e feminino e daí o corpo tem tudo a ver com isso. Por exemplo, se é do gênero feminino tem a diferença do corpo né, daí é diferente do homem, acho que é isso (risos), mas tem relação.

Como salienta Louro (2000), a dificuldade em distinguir corpo, sexualidade e gênero expressa a dificuldade em definir onde termina a natureza e onde começa a cultura na formação humana. Por tudo isso, é imprescindível admitir que os corpos "são" aquilo que "são" em um determinado momento e lugar em razão de sua estreita vinculação com a cultura: linguagem, signos, convenções e tecnologias usadas para referi-los. O corpo "fala" por meio desses códigos, adornos, cheiros e gestos, que podem ser "lidos" dentro do contexto cultural em que está inserido.

A professora P2(M), por exemplo, pretendeu fazer uma relação entre gênero e sexualidade ao considerar o conceito de homossexualidade como uma manifestação da sexualidade dos indivíduos. Porém, ao considerar os homossexuais como um gênero, demonstrou confundir os conceitos de gênero e sexualidade, como evidencia sua fala, “[...] hum, não sei, é que no caso têm os homossexuais, é um gênero e tem relação com a sexualidade".

Com base nas colocações de Louro (1997), a distinção entre corpo, sexualidade e gênero, por parte dos/as docentes, depende de um distanciamento conceitual do que parece natural. O que é natural e normal? Os corpos são apenas biológicos? Afinal, nascer com pênis ou com vulva faz alguém ser "masculino" ou "feminino"? Para a autora, a resposta é não, apesar de que essa posição se baseia

[...] em concepções ou em teorias que supõem dois universos opostos: o masculino e o feminino. Também aqui é evidente que a matriz que rege essa dicotomia é, sob o ponto de vista da sexualidade, restritamente heterossexual. Como uma conseqüência, todos os sujeitos e comportamentos que não se "enquadrem" dentro dessa lógica ou não são percebidos ou são tratados como problemas e desvios (LOURO, 1997, p. 76).

Depoimentos de alguns/mas professores/as expressaram suas dúvidas e inquietações sobre o tema fazendo supor a existência de certa instabilidade em seus conceitos de gênero, sexualidade e corpo. Compartilhando a posição de Louro (1997), essas manifestações são fundamentais para a abertura de novas possibilidades de ser do homem e da mulher. Esse é o caso da professora P5(M), que mostrou contradições em sua fala. Afirmou que "não, não vejo uma diferença. A gente sabe que tem, que existe, mas pra mim ao meu ver, não!". Ao mesmo tempo em que acredita na existência de uma diferença entre os conceitos de gênero, corpo e sexualidade, afirma, contudo, 
que em sua concepção não há. Confunde um pouco mais sua resposta ao manifestar que é preciso deixar claro aos alunos "o que é menino e o que é menina":

P5(M) - Eu acho que não, porque a gente tem que tratar diferentemente a menina e o menino dentro de sala de aula, querendo ou não. Eu tento, não definir isso, porque os dois são meus alunos independente de ser do sexo, masculino ou feminino. Não vejo uma diferença dos dois, pra mim eu vou tratar igual.

FF - Você poderia explicar melhor as relações entre gênero, sexualidade e corpo?

P5(M) - É aquilo, você precisa trabalhar esse lado, principalmente 5a série que vai tá aflorando, então você vai ter que definir isso perante os alunos, você vai ter que saber tem que ter, como se diz, um "gingado" de poder definir, mas é aquilo, na hora de passar pra eles você tem que deixar consciente "olha você é menino! Olha vocêé menina!".

A preocupação da professora P5(M) em "tratar diferente" meninos e meninas sugere, de um lado, questionamento aos padrões e, de outro, perpetuação da desigualdade. Sua resposta sugere novamente dúvida e, talvez, abertura para discussões sobre o gênero no âmbito escolar.

P7(H) e P12(M) responderam a questão centrando-se em sua disciplina Educação Física - e ressaltaram a relevância do movimento e domínio do corpo. Ambos compreenderam que há relação entre os três aspectos, mas não conseguiram verbalizar essa diferença. P7(H) afirmou que "tem relação e tem diferença, porque gênero já foi falado a questão do masculino e feminino. Sexualidade tem a ver bastante na questão das crianças, tem uns que são muito aflorados e a questão do corpo né, pelo o que eu conheço, é o nosso objeto de estudo [...]”. P12(M) relacionou as consequências da falta do domínio do corpo e, ao mesmo tempo, lembrou que o fato de as crianças se tocarem revela que estão descobrindo o seu corpo, e não está diretamente relacionado a uma questão sexual.

Na segunda entrevista, nenhum dos sujeitos se referiu à relação gênero entre sexualidade e corpo como biológica. Durante os encontros de intervenção, essas questões foram ressaltadas, e que, embora haja a relação biológica, ela não é a única, porque há uma variedade de fatores que relacionam esses conceitos em diversas dimensões.

\section{Categoria C: Não respondeu/ não explicou}

Na primeira entrevista, a professora P11(M) afirmou existir uma relação entre os conceitos, mas não a explicou. Mostrou-se com poucas condições de falar sobre o 
assunto em razão de sua educação "muito rígida", que não permitia tocar em certos assuntos: "Eu pensei assim que você ia falar no geral, das minhas dúvidas, o que eu tenho, eu me deparando em casa na educação que eu tive em casa [...] foi uma educação muito rígida [...] fica subtendido, que as pessoas não podem falar às claras”.

P11(M) - Com relação ao corpo, o sexo tudo isso, fica meio assim pra mim, fica difícil eu me deparo numa situação difícil, às vezes na minha casa, na escola, é difícil. [...] eu sinto assim, que eu tenho muita dificuldade falando sobre esses assuntos, falando sobre sexo, assim na brincadeira é uma coisa, agora o meu particular tá conversando sobre isso eu acho muito estranho porque eu tive essa educação e essa educação foi meio reprimida né [...].

Na segunda entrevista, mais uma vez P5(M) não respondeu a questão, centrando-se nas considerações de que "[...] referente à sexualidade, não tem como confundir um menino com uma menina, cada um desenvolve o seu, mas de uma maneira diferente". Nota-se uma confusão conceitual entre sexo e sexualidade. Mesmo após a solicitação de explicações sobre a relação, ela continua "As meninas, assim, eu vejo assim, às vezes elas desenvolvem mais rápido a sexualidade, elas estão mais a frente do que os meninos".

\section{Algumas Considerações}

Comparados os dados obtidos na primeira e segunda entrevista com os docentes evidenciou um movimento de ampliação e (re)construção de seus conceitos sobre gênero que sugere a abertura do grupo a outras possibilidades de ser, agir e pensar, não restrita aos padrões determinados socialmente. Abertura válida tanto para si mesmo como para seus alunos, como evidencia a fala da professora $\mathrm{P} 12(\mathrm{~F})$, durante o processo de intervenção psicopedagógica "Essa semana eu, eu me policiei nesse sentido, estava lendo as atividades feitas no caderno né, e quando vinha as meninas e os meninos eu me policiei em elogiar os dois [...]".

Sem dúvida, há um grande desafio em desconstruir dogmas em relação ao gênero, pois envolvem preconceitos morais, religiosos e científicos produzidos pela tradição social e cultural. Ao perceberem que o poder econômico, social, político e cultural que circula pela sociedade geram estratégias de produção e reprodução de saberes e de identidades, incluindo a de gênero, os docentes parecem ter se dado conta de que o ensino desse tema não implica somente transmitir conhecimentos, e sim refletir sobre sua arbitrariedade. Daí a importância de interrogar, problematizar e 
tomar consciência dos efeitos das práticas sociais que ao selecionarem conteúdos, pensamentos e ações como verdades universais podem silenciar outras formas possíveis de ser, sentir e pensar.

A "diferença" masculino/ feminino tem implicações significativas na instituição escolar, pois, conforme vários estudos demonstram (BOURDIEU, 1995; LOURO, 2007), são reproduzidas desigualdades sociais, evidentemente o mesmo ocorre com as relações de gênero. Todavia, a partir do momento que as relações sociais e de poder são questionadas e discutidas, os indivíduos são capazes de compreender o papel contraditório da instituição escolar. Se por um lado, a escola reproduz as desigualdades sociais, culturais, de gênero, por outro, pode ser um ambiente que desenvolva essas questões por meio do processo de tomada de consciência dos sujeitos sobre seus pensamentos e ações.

Um diálogo necessário à escola é abordar as subjetividades, os sentimentos, os anseios, os conflitos, as ambigüidades e as contradições dos indivíduos. Sobretudo, os professores precisam compreender que nenhuma identidade é natural, é produzida pelas crenças, valores, costumes, hábitos, normas e regras trazidas pelas diferentes comunidades de práticas nas quais os sujeitos viveram e vivem.

Gênero e sexualidade são dimensões que integram a identidade pessoal de cada indivíduo, pois são produzidas pelos efeitos do poder e se transformam conforme os valores sociais vigentes em uma dada época. Em síntese, é a cultura que constrói o gênero e representa as atividades como masculinas e femininas de acordo com os interesses que circulam em determinado momento. É necessário, portanto, que as pessoas tenham essa consciência, sobretudo, no ambiente escolar para que as práticas escolares contribuam de forma crítica na construção de identidade, ou seja, possibilitando aos indivíduos mais conhecimentos sobre si, sobre o outro e sobre o mundo.

\section{Referências}

BOURDIEU, Pierre. A dominação masculina. Revista Educação \& Realidade, Porto Alegre, v. 20, n. 2, p. 133-184, jul./ dez. 1995.

COSTA, M. V. Pesquisa-ação, pesquisa participativa e política cultural da identidade. In: COSTA, M. V. (Org.). Caminhos investigativos II: outros modos de pensar e fazer pesquisa em educação. Rio deJ aneiro: DP\&A, 2002. p. 91-115.

COSTA, Marisa Vorraber. Currículo e política cultural. In: COSTA, M. V. (Org.). O currículo nos limiares do contemporâneo. 2. ed. Rio de J aneiro: DP\&A, 1999. p. 37-68. 
FOUCAULT, Michel. A história da sexualidade: a vontade de saber. 18. ed. Rio de Janeiro: Graal, 1988. v. 1.

FOUCAULT, Michel. Microfísica do poder. 4. ed. Rio deJ aneiro: Graal, 1984.

HOOKS, B. Eros, erotismo e o processo pedagógico. In: LOURO, G. L. (Org.). O corpo educado: pedagogias da sexualidade. Belo Horizonte: Autêntica, 2007. p. 113-123.

LOURO, Guacira Lopes. Corpo, escola e identidade. Educação e Realidade, Porto Alegre, v. 25, p. 59-76, jul./ dez. 2000.

Gênero, sexualidade e educação: uma perspectiva pós-estruturalista.

Petrópolis: Vozes, 1997.

. O currículo e as diferenças sexuais e de gênero. In: COSTA, M. V. (Org.). O currículo nos limiares do contemporâneo. 2. ed. Rio deJ aneiro: DP\&A, 1999. p. 85-92.

Pedagogias da sexualidade. In: LOURO, G. L. (Org.). O corpo educado: pedagogias da sexualidade. Belo Horizonte: Autêntica, 2007. p. 7-34.

MEYER, Dagmar E. Etnia, raça e nação: o currículo e a construção de fronteiras e posições sociais. In: COSTA, M. V. (Org.). O currículo nos limiares do contemporâneo. 2. ed. Rio de J aneiro: DP\&A, 1999. p. 69-83.

MEYER, Dagmar. Gênero e educação: teoria e política. In: LOURO, Guacira Lopes; NECKEL, J ane Felipe; GOELLNER, Silvana Vilodre. (Org.). Corpo, gênero e sexualidade: um debate contemporâneo na educação. Petrópolis: Vozes, 2003. p. 9-27.

SCOTT, J oan. Gênero: uma categoria útil de análise histórica. Educação e Realidade, Porto Alegre, v. 20, n. 2, p. 71-99, jul./ dez. 1995.

SILVA, Roseli Pereira. Cinema e educação. São Paulo: Cortez, 2007.

SILVA, Tomaz Tadeu da. A produção social da identidade e da diferença. In: SILVA, T. T. (Org.). Identidade e diferença: a perspectiva dos estudos culturais. 7. ed. Petrópolis: Vozes, 2007. p. 73-102.

SOIHET, Rachel. Pisando no "sexo frágil”. Nossa História, São Paulo, ano 1, n. 3, p. 1519, jan. 2004.

SOUZA, Nádia Geisa Silveira de. Representações de corpo-identidade em histórias de vida. Educação e Realidade, Porto Alegre, v. 25, n. 2, p. 95-116, jul./ dez. 2000.

WEEKS, J effrey. O corpo e a sexualidade. In: LOURO. G. L. (Org.). O corpo educado: pedagogias da sexualidade. Belo Horizonte: Autêntica, 2007. p. 7-34.

Colaboração recebida em 18/ 08/ 2009 e aprovada em 17/ 06/2010. 